\title{
Children at danger: injury fatalities among children in San Diego County
}

\author{
Andrea M. A. Fraga · Gustavo P. Fraga • \\ Christina Stanley · Todd W. Costantini • \\ Raul Coimbra
}

Received: 18 April 2009/Accepted: 31 December 2009/Published online: 19 January 2010

(C) The Author(s) 2010. This article is published with open access at Springerlink.com

\begin{abstract}
External causes of death are important in the pediatric population worldwide. We performed an analysis of all injury-fatalities in children between ages zero and 17 years, between January 2000 and December 2006, in San Diego County, California, United States of America. Information was obtained from the County of San Diego Medical Examiner's database. External causes were selected and grouped by intent and mechanism. Demographics, location of death and relation between the injury mechanism and time of death were described. There were 884 medico-legal examinations, of which 480 deaths were due to external causes. There majority were males (328, $68.3 \%)$ and whites $(190,39.6 \%)$. The most prevalent mechanism of injury leading to death was road traffic accidents (40.2\%), followed by asphyxia (22.7\%) and penetrating trauma $(17.7 \%)$. Unintentional injuries occurred in $65.8 \%$ and intentional injuries, including homicide and suicide, occurred in 24.2 and $9.4 \%$, respectively. Death occurred at the scene in 196 cases $(40.9 \%)$. Most deaths occurred in highways (35.3\%) and at home (28\%). One
\end{abstract}

\footnotetext{
A. M. A. Fraga - G. P. Fraga - T. W. Costantini .

R. Coimbra $(\bowtie)$

Division of Trauma, Surgical Critical Care, and Burns, Department of Surgery, San Diego (UCSD) School of Medicine, University of California San Diego, 200 West Arbor Dr, \#8896, San Diego, CA 92103-8896, USA

e-mail: rcoimbra@ucsd.edu
}

A. M. A. Fraga - G. P. Fraga

Faculty of Medical Sciences, University of Campinas (UNICAMP), São Paulo, Brazil

C. Stanley

Office of the Chief Medical Examiner, County of San Diego,

San Diego, CA, USA hundred forty-six patients $(30.4 \%)$ died in the first $24 \mathrm{~h}$. Seven percent died 1 week after the initial injury. Among the cases that died at the scene, $48.3 \%$ were motor vehicle accidents, $20.9 \%$ were victims of firearms, $6.5 \%$ died from poisoning, 5\% from hanging, and $4 \%$ from drowning. External causes remain an important cause of death in children in San Diego County. Specific strategies to decrease road-traffic accidents and homicides must be developed and implemented to reduce the burden of injuryrelated deaths in children.

Keywords Childhood - Epidemiology · External causes · Injury $\cdot$ Injury prevention

\section{Introduction}

Injury is the leading cause of death and long term disability in children worldwide and it is a significant contributor to healthcare costs in most industrialized countries [1-3].

Despite improved education and prevention initiatives, injuries are the first cause of death beyond the first year of life. Annually, injury kills more than 5 million people and 875,000 of them are children. In addition, it accounts for $9 \%$ of global mortality and it is a threat to health in every country [4]. In 2005, there were 173,753 deaths caused by injury in the USA and 1,856 children died after unintentional or intentional injury in California [5].

Databases and trauma registries have been developed in the last three decades as means to document and follow trauma trends and outcomes. The development of emergency medical systems, trauma programs, and injury prevention strategies depend on comprehensive injury demographics and trends. The data accumulated in these registries can be analyzed and used to influence local 
prevention initiatives and legislation. Examples are the current National Trauma Data Bank of the American College of Surgeons Committee on Trauma and the Injury Statistics Query and Reporting System, a web-based system developed by the National Center for Injury Prevention and Control to provide reports of injury statistics [5]. There are also trauma systems and trauma centers that maintain their own internal registry. An example is the one part of the San Diego County Trauma System which became operational in 1984.

The superiority of primary injury prevention over secondary prevention and treatment is widely accepted. Primary injury prevention strategies identify risk factors in an attempt to intervene before the event occurs. Engineering, enforcement, and education, when combined, play a significant role in the reduction of injuries. For example, in car crashes the engineering would include anti-lock brakes, enforcement would encompass traffic laws, and education would include alcohol and drug use awareness.

Developing an appropriate approach towards injury prevention depends on detailed knowledge of the epidemiology of injuries. Our goal was to analyze all fatal injuries among children less than 18 years old that occurred between 2000 and 2006 in San Diego County, to identify different age groups at risk, and to alert for potential prevention opportunities to decrease childhood mortality.

\section{Methods}

San Diego County covers an area of 4,238 square miles and has a population of $3,098,269$ people. Seventy percent of the population under 18 years is non-Hispanic (50\% white, $10 \%$ asian, 5\% black; 5\% other) and 30\% Hispanic [6]. Major interstate routes traverse the region, contributing significantly to the number of road traffic injuries. The San Diego County Trauma System started in 1984 and it is composed of six trauma centers. The Rady's Children's Hospital is the primary receiving center for pediatric trauma and the University of California San Diego Level-1 Trauma Center is the back up pediatric trauma center for San Diego County.

All traumatic deaths that occur in San Diego County, irrespective of the location of the fatality, are investigated by the Medical Examiner's Office to promote safe and livable communities by certifying the cause and manner of death for all homicides, suicides, accidents and sudden/ unexpected natural deaths. In addition, it provides related forensic services, assistance, and education to families of the deceased, as well as to public and private agencies, in a professional and timely manner. Data analysis including a synopsis of the case, patient demographics, autopsy findings and mechanism of injury are entered into a database. San Diego County had a Coroner System until March 31, 1990, when it was replaced by the current Medical Examiner System. A Medical Examiner is a forensic pathologist (Medical Doctor) with particular expertise in investigating violent, sudden and unexpected, suspicious or unattended deaths.

The data used in this analysis was abstracted from the County of San Diego Medical Examiner's database. We selected external causes of death using e-codes and grouped injuries by intent: unintentional, self-inflicted (suicide), homicide and undetermined; and by mechanism: poisoning, burning, cut/stab, firearm, fall, transport related (passengers, drivers in automobiles or pedestrians hit by an automobile, trucks, bicycles, motorcycles, all-terrain vehicles or train), assaults, asphyxia (drowning, hanging, suffocation, and strangulation), and others. In the study we used the vital statistics age groupings for children: $<1$ year, 1-4 years, 5-9 years, $10-14$ years, and 15-17 years of age and made a correlation with the intent and the mechanism. We described the demographics and location of death and analyzed the relationship between the injury mechanism and time of death.

The study was approved by the UCSD Institutional Review Board and its Human Research Protections Program.

\section{Results}

From January 1, 2000, to December 31, 2006, the Medical Examiner's Office in San Diego County, California, USA, performed 884 medico-legal examinations in individuals between 0 and 17 years of age, of which 480 died by external causes. The remaining deaths were confirmed by other causes and were not included in the study.

There were 328 (68.3\%) males and 152 (31.7\%) females. There were 190 (39.6\%) whites, 189 (39.4\%) Hispanics, 56 (11.6\%) African-Americans and 45 (9.4\%) others. The mortality rate was two folder-higher (17.5 versus 8.8 per 100.000 inhabitants) in African-Americans compared to white population.

The most prevalent mechanism of injury leading to death was road traffic related (193 cases-40.2\%), followed by asphyxia (109 cases-22.7\%) and penetrating trauma ( 85 cases $-17.7 \%$ ) (Table 1 ).

Road traffic related was the mechanism in more than half of all deaths in three groups: 5-9 years, 10-14 years and $15-17$ years. The majority were passengers in automobiles, followed by pedestrian struck. Accidents involving all-terrain vehicles represented $4.6 \%$, motorcycle was less frequent $(3.1 \%)$ and there was one accident involving a train crash. 
Table 1 Mechanism of injury by age group

\begin{tabular}{|c|c|c|c|c|c|c|}
\hline Mechanism & Total & $\begin{array}{l}<1 \text { year } \\
61(12,7 \%)\end{array}$ & $\begin{array}{l}1-4 \\
86(17,9 \%)\end{array}$ & $\begin{array}{l}5-9 \\
39(8,1 \%)\end{array}$ & $\begin{array}{l}10-14 \\
72(15,0 \%)\end{array}$ & $\begin{array}{l}15-17 \\
222(46,3 \%)\end{array}$ \\
\hline Road traffic related & 193 & $7(11,5 \%)$ & $22(25,5 \%)$ & $27(69,2 \%)$ & $36(50,0 \%)$ & $101(45,5 \%)$ \\
\hline Passenger & 119 & 7 & 9 & 12 & 18 & 73 \\
\hline Pedestrian & 51 & - & 13 & 10 & 12 & 16 \\
\hline Off-road & 9 & - & - & 2 & 4 & 3 \\
\hline Bicycle & 8 & - & - & 3 & 2 & 3 \\
\hline Motorcycle & 6 & - & - & - & - & 6 \\
\hline Asphyxia & 109 & $30(49,2 \%)$ & $35(40,8 \%)$ & $7(17,9 \%)$ & $11(15,1 \%)$ & $26(11,5 \%)$ \\
\hline Drowning & 59 & 8 & 33 & 4 & 4 & 10 \\
\hline Suffocation & 24 & 19 & 1 & 2 & - & 2 \\
\hline Hanging/strangulation & 26 & 3 & 1 & 1 & 7 & 14 \\
\hline Firearms & 77 & $1(1,6 \%)$ & $4(4,6 \%)$ & - & $11(15,1 \%)$ & $61(27,4 \%)$ \\
\hline Assault & 43 & $16(26,2 \%)$ & $17(19,8 \%)$ & $3(7,7 \%)$ & $3(4,5 \%)$ & $4(1,8 \%)$ \\
\hline Poisoning & 24 & $4(6,6 \%)$ & $1(1,2 \%)$ & - & $4(5,5 \%)$ & $15(6,8 \%)$ \\
\hline Fall & 10 & - & $3(3,5 \%)$ & $1(2,6 \%)$ & $2(2,8 \%)$ & $4(1,8 \%)$ \\
\hline Stabb & 8 & - & - & - & $2(2,8 \%)$ & $6(2,7 \%)$ \\
\hline Burn related & 8 & $1(1,6 \%)$ & $2(2,3 \%)$ & $1(2,6 \%)$ & $1(1,4 \%)$ & $3(1,4 \%)$ \\
\hline Others & 8 & $2(3,3 \%)$ & $2(2,3 \%)$ & - & $2(2,8 \%)$ & $2(0,9 \%)$ \\
\hline
\end{tabular}

Table 2 Death rates according to intent

\begin{tabular}{lcccccc}
\hline Intent & Total & $<1$ ano & $1-4$ & $5-9$ & $10-14$ & \multicolumn{1}{c}{$\begin{array}{l}15-17 \\
222\end{array}$} \\
\hline Unintentional & & 61 & 86 & $65(75.6 \%)$ & $36(92.3 \%)$ & $48(66.7 \%)$ \\
Homicide & $316(65.8 \%)$ & $39(63.9 \%)$ & $21(24.4 \%)$ & $3(7.7 \%)$ & $11(15.3 \%)$ & $128(57.7 \%)$ \\
Suicide & $116(24.2 \%)$ & $22(36.1 \%)$ & - & - & $11(15.3 \%)$ & $34(15.3 \%)$ \\
Undetermined & $45(9.4 \%)$ & - & - & - & $2(2.7 \%)$ & $1(0.4 \%)$ \\
\hline
\end{tabular}

Among the children younger than five years of age, the main cause of death was asphyxia. Positional asphyxia due to overlaying was the most frequent cause of death in infants. A two month old child died after a foreign body aspiration. A four month old child was asphyxiated with a plastic bag over the face. Drowning was the leading cause of death among all cases of asphyxia in the age group 1-4 years.

Penetrating trauma was the third cause of death in all age groups. There were 77 cases $(90.5 \%)$ due to firearms and 8 cases $(9.5 \%)$ due to stab wounds. Penetrating injury was mostly prevalent in the 15-17 year age group and the intent was homicide in the majority of the cases.

Assault was the cause of death in 43 children (8.9\%), the majority being five years of age or less. A 16 year-old boy died after a spinal cord injury during a football game.

There were 24 deaths $(5 \%)$ due to drug-related poisoning; $19(79.1 \%)$ occurred in the 15 year age group or older, and most of them were unintentional.
Ten deaths $(2.0 \%)$ were caused by falls. Six were accidental falls, while the remaining includes jumping from a bridge, a hotel roof and balconies.

Nine deaths $(1.7 \%)$ were fire and burn related, five being thermal injuries. In addition, electrocution occurred in two cases and two (0.4\%) suffered smoke inhalation during wildfires.

When the data was analyzed by intent, unintentional injuries occurred in $65.8 \%$ and road traffic-related accidents and asphyxia were the most common. Intentional injuries, including homicide and suicide, occurred in 24.2 and $9.4 \%$, respectively. Injuries of undetermined intent represented only a small number of the total (Table 2).

Homicides were mostly caused by firearms (60 cases$51.7 \%$ ) and blunt force (40 cases-34.5\%). Homicides due to firearms and stab wounds were more often seen in older children, whereas assaults were more frequent in the younger groups. Homicides caused by asphyxia occurred in 
Fig. 1 Location of the deaths occurred at the scene

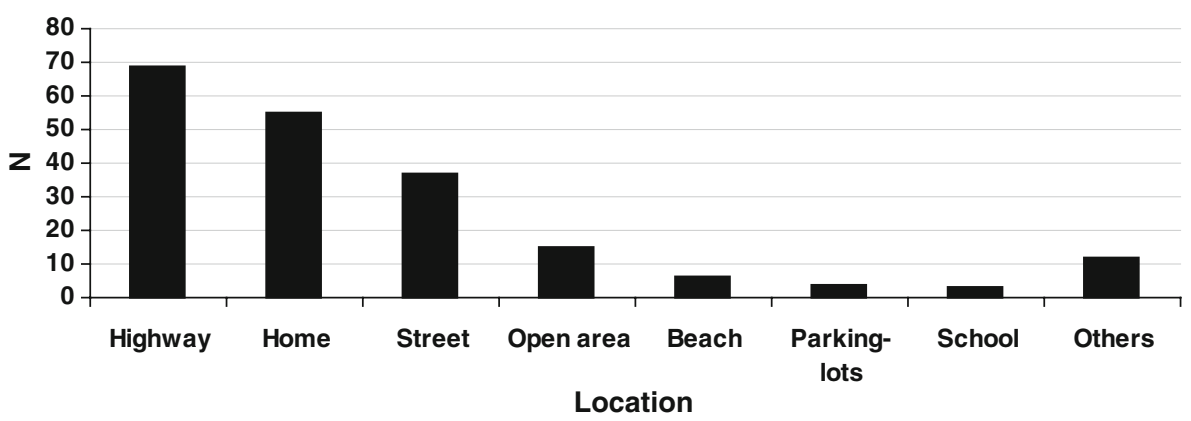

$5.2 \%$ while poisoning and intentional burns represented $0.8 \%$ each.

Deaths resulting from suicide were caused by asphyxia in $37.7 \%$ of the cases and the most frequent mechanism was hanging. Firearms were responsible for $35.6 \%$ of all suicide-related deaths. The majority $(71.1 \%)$ of the children victims of suicide were male. Other mechanisms included poisoning (13.4\%), falls (8.9\%), burns (2.2\%) and motor vehicle accident (2.2\%). Most of the suicides (75.6\%) occurred in the group of $15-17$ years and $71.1 \%$ were males.

Death in this children population occurred at the scene in 201 cases (41.9\%; Fig. 1). One hundred forty-six patients $(30.4 \%)$ died in the first $24 \mathrm{~h}$ and 34 patients (7.1\%) died 1 week after the initial injury. Among the cases that died at the scene, $48.3 \%$ were motor vehicle accidents, $20.9 \%$ were victims of firearms, $6.5 \%$ died from poisoning, $5 \%$ from hanging, and $4 \%$ from drowning. The other less frequent causes of scene death were suffocation, blunt forces, falls, stabbings and burns (Table 3).

Table 3 Time interval between mechanism of injury and death

\begin{tabular}{|c|c|c|c|c|c|}
\hline \multirow[t]{2}{*}{ Mechanism (n) } & \multicolumn{5}{|c|}{ Time interval } \\
\hline & $\begin{array}{l}\text { Scene } \\
201\end{array}$ & $\begin{array}{l}<24 \mathrm{~h} \\
146\end{array}$ & $\begin{array}{l}1 \text { day } \\
56\end{array}$ & $\begin{array}{l}2-7 \text { days } \\
43\end{array}$ & $\begin{array}{l}>7 \text { days } \\
34\end{array}$ \\
\hline Asphyxia/suffocation & 7 & 11 & 1 & 2 & 3 \\
\hline Assault & 5 & 12 & 13 & 7 & 6 \\
\hline Stab & 5 & 2 & 1 & - & - \\
\hline Drowning & 8 & 23 & 11 & 8 & 9 \\
\hline Poisoning & 13 & 5 & 1 & 2 & 3 \\
\hline Fall & 4 & 3 & 1 & 1 & 1 \\
\hline Burn related & 5 & 2 & - & - & 1 \\
\hline Firearms & 42 & 24 & 8 & 1 & 2 \\
\hline Hanging/strangulation & 10 & 12 & 1 & 2 & 1 \\
\hline Road traffic related & 97 & 51 & 18 & 19 & 8 \\
\hline Others & 5 & 2 & - & 1 & - \\
\hline
\end{tabular}

\section{Discussion}

The data presented herein highlight the recent epidemiologic profile of injury related mortality in children in San Diego County. Mortality data is used to develop intervention strategies and to guide pediatric counseling on injury prevention. Effective strategies depend on detailed injury data showing how risk changes as children develop and grow older.

Pediatric deaths due to external causes remain a major public health problem and constitute the number one cause of demise in that patient population. In San Diego County, death rate approaches $10 \%$ in the pediatric trauma population and the majority of deaths are caused by roadtraffic accidents and violence.

In the present study there were 16.2 deaths per 100.000 inhabitants in the group age $0-17$ years and 8.8 deaths per 100.000 inhabitants below 18 years of age caused by external causes. In England and Wales, in the 2001 census, 4 per 100.000 children age $0-15$ years died from injuryrelated causes [7]. In Sweden, from 1991 to 1995, injury mortality was 19.3 per 100.000 and $71.6 \%$ of all injuryrelated deaths occurred in individuals younger than 20 years of age [8]. Another study showed an average annual injury death of 55.1 per 100.000 inhabitants in Mexico City [9]. In Brazil, fatal injury rates according to age per 100.000 population in 2003 were 17.7 in children less than 5 years, 10.7 in the 5-9 age group, 14.8 in the 10 14 age group, and 74.7 in 15-19 year group [10]. These rates suggest that socioeconomic factors influence injuryrelated mortality rates.

We observed that the majority of the deaths occurred in males (two fold higher), which is in accordance to data reported by others [1, 11-14]. This finding probably reflects the impulsive nature and curiosity attributed to the male gender.

In terms of race, most injuries in our study occurred in whites (39.6\%) and in Hispanics (39.4\%). The analysis demonstrates changes in mortality in different ethnic groups (Hispanics, White, and African-Americans) which 
is similar to data published by Pressley et al. [15]. Those authors found a higher injury risk in the African-American aged 0-4 years population as a result of residential fire, suffocation, poisoning, motor vehicle accidents and firearms. The small differences between the two studies may be explained by the racial distribution of the population in these two distinct geographic areas (San Diego and all USA), which highlights the importance of a detailed characterization of the population in epidemiologic studies.

The analyses of our data show that unintentional deaths constituted $65.8 \%$ of all deaths from injury followed by homicides $(24.2 \%)$ and suicides $(9.4 \%)$. In the USA, unintentional injury leading to death predominates in all age, races, and gender groups.

Suicide was the second cause in the 10-14 year age group and homicide by the use of firearms was the second cause in the 15-24 year age group [16]. In Canada, unintentional injuries accounted for an average of $86 \%$ of the total injury-related deaths, whereas intentional injuries represented only a small proportion of the total deaths [1]. The same distribution was noted in Sweden and in others less developed countries such as Nepal, South Africa and Brazil [8, 17-19]. One study conduced in Denver between 1996 and 2004 at a regional level 1 pediatric trauma center showed that unintentional trauma was a major cause of morbidity and mortality among children [20]. In Recife, a particularly violent city in northeast Brazil, the most frequent cause of death in adolescents by intent was homicide [12].

Homicide was the second most common cause of death in our study. In younger ages the most common mechanism was blunt trauma while in older age groups penetrating mechanisms predominated. This reflects the rising violence in our society although, neither a single indicator nor a single source of information is sufficient to describe the magnitude, health, and social consequences of violence. The manufacture, distribution, sale, acquisition, storage, transportation, carrying, and use of firearms in the United States are regulated by a complex array of federal, state, and local laws and regulations. There are several laws related to firearms: Bans on specified firearms or ammunition, restrictions on firearm acquisition, waiting periods for firearm acquisition, firearm registration and licensing of owners, zero tolerance laws for firearms in schools, and the child access prevention (CAP) laws. These laws are designed to limit children's access to and use of firearms in homes. The laws require firearms owners to store their firearms locked, unloaded, or both, and make the firearm owners liable when children use a household firearm to threaten or harm themselves or others. In three states with CAP laws (Florida, Connecticut, and California), this crime is a felony; in several others it is a misdemeanor. A well designed study found insufficient evidence to determine the effectiveness of any of the firearms laws reviewed for preventing violence, therefore there is a significant need for future research in this important area of injury prevention [21].

Nowadays, violence is a major public concern for all societies and in low and middle-income countries the problem is even more important. Over the period from 1980 to 2002, homicide rates more than doubled in Brazil [10]. In South Africa, mortality rates from firearm injury among children and adolescents nearly tripled during 1992 to 1996 . Ritual murders, usually for traditional medicinal purposes, are also practiced by some Africans states, and the victims are often children [18].

Although suicide has been reported as an important and frequent cause of death, in our study $9.4 \%$ of the deaths were due to suicide. Depression, mental health disorders, social isolation, drugs and alcohol are related to the occurrence and prevalence of suicide [2, 22]. Males are three times more likely than females to complete suicide, but females are more likely to exhibit persistent suicidal ideation and to engage in self-injury or self-harm behavior, without expressed intent to die. A previous suicide attempt is the strongest predictor of completed suicide, increasing the risk 30 -fold in male adolescents. Probably affective factors such as impulsivity, poor affect regulation, aggression, especially when paired with adverse life events, are linked to higher suicide risk in males. Access to mental health facilities with suicide crisis intervention programs, timely and effective detection and treatment of mental disorders have improved suicide rates at San Diego County [2]. Nevertheless, suicide remains a major problem in our society and methods for reducing it rely on the identification of patients at risk $[2,8,9,17,22]$. Initiating programs among middle school aged children before the steep rise in suicide occurs would seem beneficial [23].

According to the World Health Organization, road traffic injury is a major global public health and development problem that will worsen in the years ahead if no significant steps are taken to prevent it [24]. In our study, the most common cause of death in all children over 5 years of age was motor vehicle crashes. This data is similar to those reported in studies done worldwide and independent of the social economic level of the country [1, 8-10, 13, 18, 25-28]. In low and middle-income countries, a large proportion of the road crash victims are pedestrians and cyclists. This was noted in Mexico, Colombia, Brazil, as well as in northern Manhattan, New York City [9, 10, 28, 29]. In Mexico, Colombia, and Brazil, the high frequency of pedestrian fatalities may be related to the influx of rural migrants into the city who are not accustomed to heavy traffic and the conventions of pedestrian behavior with the traffic. In northern Manhattan, walking is an important mode of transportation which contributes to the 
high incidence of child pedestrian injuries in that region [28].

In our study, asphyxia was the first cause of death in children younger than 5 years of age. Suffocation was more prevalent in infants and drowning predominated in 1-4 year olds. These results have also been reported in several other studies $[1,15,30]$. Perhaps because of the warm weather and backyard swimming pools in California, drowning is the leading cause of death in children aged 1-4 years. The most important concern about this issue is that a significant number of asphyxiation-related deaths could have been prevented. Rimsza et al. [25] in a study to determine the preventability of pediatric deaths in Arizona found that $90 \%$ of the drowning-related deaths that occurred in backyard pools were considered preventable. Also, the infant's sleeping position and health sleeping habits are critical to prevent unintentional suffocation.

Mortality as a result of poisoning occurred in 5\% of the cases in the present study and the majority of deaths were in children older than 15 years. This result differs from Agran et al. [23] who found high incidence of poisoning in two different age-groups: 1-4 and 15-19 years. This difference may be due the fact that the main cause of poisoning in our series was drug-related, which is uncommon in younger age-groups. Also, these findings suggest that the legislation requiring child safe caps on medicines and household products are largely effective.

The location of the death was the trauma scene in $41.9 \%$ of the cases in our study. However, excluding motor vehicles accidents, the most frequent location of the death was the residence, and the most common mechanism of injury was firearm related followed by drowning, suffocation, falls, and burns. These findings have also been reported by others [3, 13, 31, 32]. The San Diego Trauma System systematically reviews all trauma-related deaths that occurred in the trauma centers in a peer-review format. However, because approximately $41 \%$ of the deaths reported in the current manuscript were declared at the scene, preventability was not determined by peer-review in those cases.

Several studies focusing on injury prevention have shown a decline in injury rates with efforts such as smoke detector alarms, child restrain systems, speed limit and driver license laws, helmets, child safety caps, window guards to protect against falls and placement of pool fences $[25,33-36]$. The first measure to reduce fatalities is primary injury prevention. These measures are specific to the host, the mechanism of injury, and the environmental and social issues surrounding an injury event. In the state of Arizona a Child Fatality Review Program (ACFRP) has systematically reviewed all deaths of children under 18 years old since 1994 and a multidisciplinary team has been able to assess the causes, preventability, and epidemiology of pediatric deaths [25]. The ACFRP defines a child's death as preventable if an individual or the community could reasonably have done something that would have changed the circumstances that led to the death. The ACFRP is an excellent example of a statewide system with a public health focus to decrease children mortality. In San Diego, a previous study from the Trauma Research and Education Foundation delineated the extent and changes over time (from 1987 to 1997) of seriously injured patients and identified a large group of potentially preventable deaths. Control programs focused populationbased injury data and effective injury prevention are the key in the reduction of serious injury [2].

Much of the historical decline in injury deaths is credited to a combination of passive and active injury prevention measures, including legislative enforcement, educational efforts, and increase access to safety products as well as economic conditions and advances in trauma care.

In conclusion, external causes remain an important cause of death in children in San Diego County. Although injury prevention programs have decreased the number of injury-related deaths in the United States, specific strategies to decrease road-traffic accidents and homicides in the age group 5-17 years and asphyxia among the children younger than five years of age must be developed and implemented to reduce the burden of childhood deaths due to external causes and injury in the community.

Acknowledgments The authors are grateful to Foundation of Support to Research of the State of São Paulo (FAPESP) to support the international scholarship awarded to Dr. Gustavo P. Fraga.

Open Access This article is distributed under the terms of the Creative Commons Attribution Noncommercial License which permits any noncommercial use, distribution, and reproduction in any medium, provided the original author(s) and source are credited.

\section{References}

1. Pan SY, Ugnat AM, Semenciw R, Desmeules M, Mao Y, Macleod M. Trends in childhood injury mortality in Canada, 19792002. Inj Prev. 2006;12:155-60.

2. Potenza BM, Hoyt DB, Coimbra R, Fortlage D, Holbrook T, Hollingsworth-Fridlund $\mathrm{P}$. Trauma research and education foundation. The epidemiology of serious and fatal injury in San Diego County over an 11-year period. J Trauma. 2004;56:68-75.

3. Nagaraja J, Menkedick J, Phelan KJ, Ashley P, Zhang X, Lanphear BP. Deaths from residential injuries in US children and adolescents, 1985-1997. Pediatrics. 2005;116:454-61.

4. World Health Organization: Violence and injury prevention. Available at: www.who.int/topics/injuries/en/ (2005). Accessed July 212008.

5. National Center for Injury Prevention and Control: Web-based Injury Statistics Query and Reporting System (WISQARS) Injury mortality Reports. Available at: www.cdc.gov/ncipc/wisquars (2004-2005). Accessed July 212008. 
6. San Diego Association of Governments: Available at http:// www.sandag.org. Accessed July 212008.

7. Edwards P, Roberts I, Green J, Lutchmun S. Deaths from injury in children and employment status in family: analysis of trends in class specific death rates. BMJ. 2006;333:119.

8. Hjern A, Bremberg S. Social aetiology of violent deaths in Swedish children and youth. J Epidemiol Community Health. 2002;56:688-92.

9. Hijar M, Chu LD, Kraus JF. Cross-national comparison of injury mortality: Los Angeles County, California and Mexico City, Mexico. Int J Epidemiol. 2000;29:715-21.

10. Gawryszewski VP, Rodrigues EM. The burden of injury in Brazil, 2003. Sao Paulo Med J. 2006;124:208-13.

11. Philippakis A, Hemenway D, Alexe DM, Dessypris N, Spyridopoulos T, Petridou E. A quantification of preventable unintentional childhood injury mortality in the United States. Inj Prev. 2004;10:79-82.

12. Barros MD, Ximenes R, de Lima ML. Child and adolescent mortality due to external causes: trends from 1979 to 1995 . Rev Saude Publica. 2001;35:142-9.

13. Nizamo H, Meyrowitsch DW, Zacarias E, Konradsen F. Mortality due to injuries in Maputo City, Mozambique. Int J Inj Contr Saf Promot. 2006;13:1-6.

14. Kanchan T, Menezes RG. Mortalities among children and adolescents in Manipal, Southern India. J Trauma. 2008;64:1600-7.

15. Pressley JC, Barlow B, Kendig T, Paneth-Pollak R. Twenty-year trends in fatal injuries to very young children: the persistence of racial disparities. Pediatrics. 2007;119:e875-84.

16. National Center for Injury Prevention and Control: Centers for Disease Control. Available at: www.cdc.gov/ncipc/factsheets/ childh.htm. Accessed July 212008.

17. Sharma G, Shrestha PK, Wasti H, Kadel T, Ghimire P, Dhungana S. A review of violent and traumatic deaths in Kathmandu, Nepal. Int J Inj Contr Saf Promot. 2006;13:197-9.

18. Meel BL. Mortality of children in the Transkei region of South Africa. Am J Forensic Med Pathol. 2003;24:141-7.

19. Gawryszeski VP. Injury mortality report for São Paulo State, 2003. Sao Paulo Med J. 2007;125:139-43.

20. Roaten JB, Partrick DA, Nydam TL, Bensard DD, Hendrickson RJ, Sirotnak AP, et al. Nonaccidental trauma is a major cause of morbidity and mortality among patients at a regional level 1 pediatric trauma center. J Pediatr Surg. 2006;41:2013-5.

21. Hahn RA, Bilukha O, Crosby A, Fullilove MT, Liberman A, Moscicki E, et al. Task force on community preventive services. Firearms laws and the reduction of violence: a systematic review. Am J Prev Med. 2005;28(2 Suppl 1):40-71.

22. Wintersteen MB, Diamond GS, Fein JA. Screening for suicide risk in the pediatric emergency and acute care setting. Curr Opin Pediatr. 2007;19(4):398-404.
23. Agran PF, Winn D, Anderson C, Trent R, Walton-Haynes L. Rates of pediatric and adolescent injuries by year of age. Pediatrics. 2001;108:E45.

24. Peden M, Scurfield R, Sleed D. World report on road traffic injury prevention. Geneva: World Health Organization. Available at: http://www.who.int/worldhealth-day/2004/infomaterials/ world_report/en/ (2004). Accessed July 212008.

25. Rimsza ME, Schackner RA, Bowen KA, Marshall W. Can child deaths be prevented? The Arizona child fatality review program experience. Pediatrics. 2002;110(1 Pt 1):e11.

26. Agran PF, Anderson C, Winn D, Trent R, Walton-Haynes L, Thayer S. Rates of pediatric injuries by 3-month intervals for children 0 to 3 years of age. Pediatrics. 2003;111:e683-92.

27. Morrison A, Stone DH. Trends in injury mortality among young people in the European Union: a report from the EURORISC working group. J Adolesc Health. 2000;27:130-5.

28. Durkin MS, Laraque D, Lubman I, Barlow B. Epidemiology and prevention of traffic injuries to urban children and adolescents. Pediatrics. 1999;103:e74.

29. Posada J, Ben-Michael E, Herman A, Kahan E, Richter E. Death and injury from motor vehicle crashes in Colombia. Rev Panam Salud Publ. 2000;7:88-91.

30. Väli M, Lang K, Soonets R, Talumäe M, Grjibovski AM. Childhood deaths from external causes in Estonia, 2001-2005. BMC Public Health. 2007;7:158.

31. Phelan KJ, Khoury J, Kalkwarf H, Lanphear B. Residential injuries in U.S. children and adolescents. Public Health Rep. 2005;120:63-70.

32. Pollock DA, McGee DL, Rodriguez JG. Deaths due to injury in the home among persons under 15 years of age, 1970-1984. MMWR CDC Surveill Summ. 1988;37:13-20.

33. Gielen AC, McDonald EM, Wilson ME, Hwang WT, Serwint JR, Andrews JS, et al. Effects of improved access to safety counseling, products, and home visits on parents' safety practices: results of a randomized trial. Arch Pediatr Adolesc Med. 2002; $156: 33-40$.

34. Hoppe-Roberts JM, Lloyd LM, Chyka PA. Poisoning mortality in the United States: comparison of national mortality statistics and poison control center reports. Ann Emerg Med. 2000;35:440-8.

35. Rivara FP. Developmental and behavioral issues in childhood injury prevention. J Dev Behav Pediatr. 1995;16:362-70.

36. Scholer SJ, Hickson GB, Ray WA. Sociodemographic factors identify US infants at high risk of injury mortality. Pediatrics. 1999;103:1183-8. 